$\underline{\text { Interview }}$

\title{
Interview with MJ Barker
}

\author{
Róisín Ryan-Flood ${ }^{1 *}$
}

Published: April 11, 2020

\section{INTRODUCTION}

Meg-John Barker is the author of a number of popular books on sex, gender, and relationships, including Queer: A graphic history (2016) and Gender: A graphic guide (2019, with Jules Scheele), How to Understand Your Gender (2017) and Life Isn't Binary (2019, with Alex Iantaffi), Enjoy Sex (How, When, and IF You Want to) (2017, with Justin Hancock), Rewriting the Rules (2018) and The Psychology of Sex (2018). They also work as a one-to-one writing mentor, as a creative consultant on various projects, and speak and train on gender, sexual and relationship diversity. They are half of the Meg-John and Justin podcast (megjohnandjustin.com) and blog and publish zines and comics on rewriting-the-rules.com. They regularly speak on their areas of expertise in the media, including Radio 4, Cosmo, and being featured in the Independent on Sunday Rainbow List. They were an academic psychologist and UKCP accredited psychotherapist for many years before focusing on writing full time. They are an internationally recognised expert on gender, sexual, and relationship diversity (GSRD) and psychotherapy, with numerous academic books and over one hundred academic papers on the topics of bisexuality, open non-monogamy, sadomasochism, non-binary gender, and Buddhist mindfulness. They co-founded the journal Psychology \& Sexuality and the activist-research organisation BiUK (The UK National Organisation for Bisexual Research and Activism), through which they published The Bisexuality Report (2012). They have advised many organisations, therapeutic bodies, and governmental departments on matters relating to gender, sexual, and relationship diversity (GSRD) including writing the British Association for Counselling and Psychotherapy (BACP) document on the topic. They've also been involved in facilitating many public events on sexuality and relationships, including Sense about Sex and the Critical Sexology seminar series (since 2006).

Firstly, thank you Meg-John Barker for participating in this special issue about feminist comics for Feminist Encounters.

I'm so happy to be included, it's great you're doing this.

It is fascinating to see that your work has expanded into the realm of comics and graphic works. Can you please say how this came about?

Absolutely. Actually, like so many things in life it wasn't planned and it nearly didn't happen. Back in 2014 my Open University colleagues Jacqui Gabb and Janet Fink had just finished this huge study of people in long-term relationships - Enduring love? - and Penguin were keen to publish a self-help book around it. They'd brought me in to lead on that because I'd published a self-help book before and was keen to do more. Then Kiera Jamieson - an editor from Icon books - contacted me out of the blue to ask whether I'd be interested in writing a graphic guide on queer theory.

My initial thoughts were (1) I'm way too busy with this other project, (2) I want to become a full-time author and that's way more likely with a big publisher like Penguin than it is with an independent like Icon, and (3) I'm not a queer theorist so who am I to write a book about queer theory?

However I felt very reluctant to turn down the book, largely because I've always been a massive fan of comics. Also I could see a huge potential to get these queer ideas - which I've personally found so helpful - out to a much wider audience than the academics, students and activists who are usually exposed to them. When I reflected on my 'not a queer theorist' concern, I figured that most academic specialists would probably struggle to convey queer theory simply enough for the general reader, whereas I've always felt that my talent was in weaving together 
complex academic and therapeutic ideas in a way which students and readers could understand and apply to their lives.

So I said 'yes' to the queer graphic book, even though it meant a lot of work and repeatedly confronting my internalised queer critic! Four years later and sadly The Secrets of Enduring Love has only just made back its advance, whereas it is the huge success of Queer: A graphic history (2016) that has meant that I've been financially able to go full time as a writer (with a good bit of downsizing!). We've already written two follow up graphic guides - on gender and sexuality - with more planned.

\section{What are the advantages of writing in a comics format?}

The main one for me is the potential to reach audiences who - for all kinds of reasons - would never read a purely text-based book. There are many groups of people who find regular books impossible, or immensely challenging to read. That can be due, for example, to various forms of neurodiversity; to disabilities or chronic health conditions that impact attention, fatigue, and focus; and/or to unfamiliarity with text-based books, or experiences of being shamed around reading at home or in the education system.

The comics format also means that these books sell in places which reach audiences beyond those who would normally seek out social science, philosophy, or even self-help style books. The book sells in comic bookshops, in queer/feminist sections of mainstream bookshops, and in galleries and museums, for example. We were also fortunate to hit the shelves at a time when non-fiction comics were becoming much more of a thing, when there was an increasing social media engagement with feminist and queer politics, and when more and more organisations and institutions were keen to put on LGBTQ events for Pride, LGBT history month, and the like. So booksellers were looking for books like ours, particularly ones which were eye-catching as Queer is.

These graphic guides are designed in a way that tells a story over the course of the book, but also in a way that means every page could be read independently to give the reader a sense of one key idea in words and pictures. This was to ensure that they would work on e-readers where people don't always read from beginning to end. The advantage of this is that many people have said they enjoy reading slowly and spending a lot of time on each page to take it in. It invites quite a different kind of reading. It also means it works as something of a coffee-table - or bathroom - book which people can pick up briefly and flick through.

One innovation I made with Queer, which I've developed through the subsequent books in the series, was to visualise the imagined readers as a group of four people who we follow through the book as they grapple with the ideas they're being introduced to. I actually did this initially to help myself to remember that I wasn't writing the book for my internalised critical queer theorist! I wanted to write it for a person who was queer themself, for a student who was struggling to understand queer theory, for an older person who was feeling lost in all the new language around gender and sexuality, and for somebody who was questioning their own gender and sexuality. But this approach to writing the book also meant that the books feel friendly to all these kinds of readers. Following the 'story' of these characters, such as it is, is also part of what makes the books an entertaining rather than purely informative read. Some of the others ways we made it entertaining were to put in visual references to popular culture, as well as visual jokes and some of the puns that queer theorists seem to be so fond of!

\section{Are there any disadvantages in relation to this format?}

No format is going to work for everyone. I'm passionate about getting better understandings of gender, sexuality, relationships, and mental health out to as wide an audience as possible, and I have to acknowledge that comics are not going to reach all audiences. Just as comics feel more friendly and accessible to some people, they're going to be off-putting to others who don't have a background of reading comics, for example, or who find them geeky and alienating. Also, of course, a visual medium isn't great for anybody who is visually disabled. Even describing such books in audio formats doesn't necessarily work well for such audiences given that it still has a visual starting point, rather than meeting them where they are.

This is why I've explored several other mediums with my work in recent years. Where I've ended up is with three to four different strands. There are the written self-help books and zines which I now write primarily with my co-author (or 'artner') Alex Iantaffi. There are the graphic guides which I collaborate on with Kiera and illustrator Jules Scheele. There's the sex and relationship podcast which I produce with Justin Hancock. And I'm also playing with writing erotic fiction which also include reflections on the key themes in my work, like consent, gender, and relationship dynamics. Hopefully between them these mediums reach audiences who engage primarily in visual or auditory ways, as well as those who get more out of words or images, and those who take information in better in the form of non-fiction or stories.

With a visual medium like comics there's also a vital question of representation. Something we've engaged with from the start is how to ensure that readers from diverse groups see themselves represented in the books, so that they know these books are for them. Some things that we've attempted to do is to ensure that people of colour are thoroughly represented throughout each book, both in our group of main characters and in the experts who they're learning from, rather than in any kind of tokenistic manner. Where there have been historical issues in the 
over-reliance on white, male experts within the discipline we have named that and reflected on it explicitly. Similarly we've endeavoured to represent disabilities beyond the standard image of a person in a wheelchair. We've also tried to represent people from different class backgrounds engaging with the material and applying it to their lives, and to represent various types of queerness beyond the most common depictions.

Obviously it's never possible to do this job of representation perfectly and there's always room for improvement, especially as a white author within my particular area of expertise. One limitation to these books is that they come from a western anglophone focus rather than covering these topics - or thinkers - in any kind of fully global way. While I feel confident addressing gender, sexuality, and so-on from a pretty interdisciplinary perspective, having studied psychology, biology, sociology, media studies, philosophy, and psychotherapy. However, I don't feel that I could do justice to the global diversity of perspectives in 176 pages, with my background. These books focus on current western perspectives, how they've developed, the impact they have, why they are so flawed, and how they might be different. Even within that I have to get my historian friend to help me out with the historical chapters as I'm very aware of the limitations of my knowledge in that field. I very much hope that future projects in this series will be able to bring a more global and decolonising perspective, given how white and anglocentric these fields are in the west.

Gender and sexuality have long been central themes of your work. What would you say are the key issues that you have explored in relation to these?

Starting this journey as I did within bi activism and scholarship, a key focus for me has always been on why sexuality and gender have been understood as binaries when clearly that doesn't match many people's - probably the majority of people's - lived experience. Research from Kinsey $(1948,1953)$ onwards has demonstrated that sexuality can be better understood on a spectrum than as a binary, but popular culture and science alike have continued to question the existence of any sexuality beyond gay or straight, and to stigmatise those who claim such identities to such an extent that we see the impact vividly in the high rates of mental health struggles in bisexual people, compared to both straight and gay people.

From questioning the gay/straight binary, I began to explore theories and research around sexual fluidity, and sexuality as multidimensional, as well as those that applied this same thinking to gender, and which questioned the whole sense of sexual or gender identities as meaningful or helpful.

Training as a sex therapist I was struck by the ways in which adhering to rigid ideals of masculinity and femininity, and endeavouring to meet up to a hetero-norm of penis-in-vagina sex, seemed to be making a lot of people very miserable. I was always motivated to include the ways in which normative understandings are bad both for those outside of them and those within them.

Engaging in social justice in these areas alerted me to the fact that activists and other members of marginalised sexual communities were often ahead of theorists and researchers in their understandings and practices. The history of the science of gender and sexuality, and even queer theory to some extent, has been a process of academics catching up with what people in these communities have often been saying and doing for years. So I've always been committed to foregrounding lived experience and presenting the 'margins' as something to learn from, rather than to be explained (as psychology and sexology have generally endeavoured to do).

\section{How have your thoughts and writing about gender and sexuality changed over time?}

I think the main shifts in recent years have been to connect gender and sexuality up more with all of the other intersecting forms of privilege and oppression, and - relatedly - to ask what non-binary and queer ways of thinking have to offer to other areas beyond gender and sexuality.

I have a much better sense - from reading intersectional feminists, and from working with colleagues like Alex Iantaffi (2011), Ros Gill (2007) and Laura Harvey (2011) - that there is no way to separate out the histories of patriarchy and queerphobia from the histories of colonialism, white supremacy, neoliberal capitalism, ableism, or any other forms of oppression or marginalisation. And that means that - personally and politically - we can't separate out our understanding or experience of gender and sexuality out from that of class, race, disability, and so on. For this reason, each of the graphic guides begins with a history of these interwoven forms of oppression, explaining how they have developed, and how they operate today. Also both the graphic guides and the "how to understand your...' books which Alex and I write together situate gender, sexuality, etc. in relation to other intersections throughout the books.

Additionally, the static, binary, unidimensional ways of understanding which have been so problematic in relation to gender and sexuality pervade in popular - and often academic - understandings of many other areas. They limit the very ways that we can think and feel about issues, because we're so trained into polarised debates where one view or experience must be 'good' or 'right' and another 'bad' or 'wrong'. This is what prompted me and Alex to write Life Isn't Binary which explores this territory and considers alternative approaches such as multiple spectrums, fluidity over time, holding multiple stories, and embracing uncertainty and paradox. 
What for you are the key issues facing writers and practitioners in the field of gender and sexuality today?

For me a vital one which impacts us all - whether creators, activists, academics, or therapists and other practitioners - is how we communicate across difference and - relatedly - how we can sit with discomfort and distress in relation to our positions of both privilege and oppression.

It seems that many of the tough conversations which happen across these areas are about the ways in which all our work inevitably excludes as well as including, oppresses as well as liberating, and harms as well as helping. We see these kinds of issues play out in polarised debates between different groups of feminist or queer activists and scholars on social media, for example, and around trigger warnings in the classroom, representations in creative work, and the ways in which therapists and mindfulness teachers often perpetuate the individualising of mental health prevalent in wider culture in ways that can exacerbate rather than ameliorating shame and self-blame. Many times the focus in such conversations is on casting blame and/or defending against perceived attack. Individuals are often claimed to be all good, or all bad, on the basis of their behaviours.

My sense is that it would be useful to put a good deal more effort into studying and understanding the processes in play in these conversations. It's important to find alternative processes which steer clear of blame and shame and instead foster the capacity to sit with the difficult feelings which these conversations inevitably bring up for all involved.

It seems to me that a key aspect in play here is that most of us find ourselves in the position of victim - or marginalised - in some of these situations, and perpetrator - or oppressor - in others. It's extraordinarily hard to hold the emotions brought up by both of these positions, especially when many of us have been traumatised personally in the past by sexual violence and/or by queerphobia. To have that trauma re-triggered by finding ourselves once more victimised - often by those we assumed to be allies, or to be confronted with the ways in which we - ourselves - have hurt others or violated their consent, can be incredibly hard to bear. But it is only by becoming able to face these things in ourselves that we can truly understand how oppression operates, speak out about it in ways which can be heard, and act accountably when we have behaved in harmful ways ourselves through ignorance or defensiveness.

You have often engaged in collaborations in your work - with co-authors and artists. What appeals to you about collaborative work of this kind?

One key thing for me is that one person can only access so much knowledge in a lifetime. I love working with people who have come to similar places to me in terms of their understandings of the topics we're writing about, but from very different backgrounds. For example, Alex's background is in the humanities, systemic therapy, and Pagan spirituality, whereas mine is in social sciences, existential therapy, and Buddhist spiritualities. That means we bring different theories, research and practices, as well as lived experiences to our work. Similarly, with Justin it feels helpful for our podcast that his experience and expertise is primarily in youth work, and working with men and straight communities, while mine is more on adults, and working with women and queers. I feel our collaborative work is much richer for the different pools of knowledge we're drawing from. It is also more creative, with the potential to reach more people, when it acknowledges the differences between us and comes from dialogue across that.

Such collaborations help me to feel more content with the knowledge that I do have, and with following the ideas that I feel most drawn to. This is preferable to getting stuck in that 'never enough' place where I'm overwhelmed by all the books, papers, videos, podcasts and websites out there: feeling I should read all of the things - regardless of whether they speak to me.

Collaborating with Jules and Kiera on the graphic guides is a different form of collaboration because it's more about us each bringing specific skills rather than knowledges. As editor Kiera puts in at least as much time and energy as Jules or I do, to the point where I question why editors are not named on the covers of such books. She is extremely talented at knowing what will be clear and accessible for a reader, and what won't. She helps to whittle down my words to our 200 words per page maximum, and to visualise which of my suggested illustrations will work well with the text. While I do illustrate comics and zines myself I have nothing near Jules's level of talent in this area. I certainly couldn't draw a convincing Butler or Lorde! So collaborating with Jules means that the books look as beautiful as they do. The fact that Jules and Kiera are also both feminists, and the relationship we've built together, mean that we can trust each other during the process, which is vital.

Something that I've learned from all these collaborations - and also from the one with Ros and Laura on our academic book Mediated Intimacy - is that consent and care have to be at the heart of any collaboration. We have to be able to reflect on the process of what we're doing, and to keep checking that it feels good to all concerned. We have to prioritise self- and other-care over meeting deadlines or producing particular kinds of outputs that we feel pressured to produce by wider systems.

This feels increasingly necessary given the hostile political climate at the moment, and the degree to which all of us are precarious and facing trauma in our own lives. Writing about sexuality as a survivor or gender as a trans 
person during the trans moral panic takes a toll, and it's vital to work with others who really understand this and are up for ensuring that the process, as well as content, of our work reflect an ethics of consent and care.

Although there is greater visibility and awareness of trans rights nowadays, significant inequalities remain for trans and non-binary people. What for you are the key equality issues facing trans and nonbinary people today?

For me the main issue is that we've been living through a moral panic around trans people and their rights now since 2017. At the beginning of that year there was a major negative news story or documentary about trans people every month. By the time we'd dealt with one we were onto the next and it felt overwhelming and exhausting for all of us in the UK trans community. However, we look back on those times now as easy compared to where we've been at since. By the end of 2017 we were at the point of one story per day, sometimes even three separate stories in the same newspaper on the same day, and this has hardly diminished since then. Imagine waking up to multiple news stories every day about how your community is to blame for multiple social ills, is lying about their very existence, and is a danger to (other) women and children.

The impact of these daily onslaughts across mainstream and social media cannot be over-estimated. For a group which already has shockingly high rates of hate crimes and discrimination, suicide and shame, we are certainly talking about significant distress, loss of life, and many failing to access the kinds of support from family, friends, and professionals that we know to be the main buffer against suicide, self-harm, and depression.

So while it is obviously important for trans people to have the same rights across all areas as those that are afforded to cis people (those who remain in the gender they were assigned at birth), for me the most vital thing at least in the UK - is to bring an end the moral panic around trans people.

There have been various controversies recently about trans rights and proponents of what has been termed 'gender critical feminism'. What are your thoughts on this?

Ah the question every trans person is waiting for in an interview! I feel that this is a great example of an area where the content of the conversation has detracted from the much more important issue of the process which is going on. People are swept up in trying to determine who is 'right' in a 'debate' between trans activists and 'gender critical feminists' rather than asking why this conversation is happening now, why it is being reported upon so gleefully by the media, and who it serves.

I'll touch briefly on the content of the conversations before moving on to process. To me the underlying questions about who counts as a 'real' man or women, whether sex/gender is biologically essential or socially constructed, and whether non-binary people exist feel somewhat pointless given that they stem from massive misunderstandings about the way gender works. To give a brief précis of the material I cover in Gender: A graphic guide: The evidence is clear that gender is a biopsychosocial phenomenon. It would be impossible to tease apart the ways our bodies and brains develop, from our lived experiences, from the cultural world which we inhabit, and all of these aspects impact the others in vastly complex, ongoing, ways throughout our lives. This means that each of us has a unique experience of gender which it makes sense to express and identify in whatever way is meaningful to us. Also, all of us go through social - and often physical - transitions during our lives around gender which affect the ways in which others read us and in which we experience our own gender (e.g. changing names, taking hormones, dressing differently, reaching different points in the lifecourse).

A trans man's experience of his masculinity will likely be radically different to that of a cis man, but it will also be radically different between two different trans men, or two different cis men, depending - for example - on whether the two men in question are gay, straight, or bi; black, white or mixed race; visibly disabled, non-disabled, or invisibly disabled. Also, on no possible measure of sex/gender is there are simple binary between male/man or female/woman. Significant numbers of both intersex and non-binary people exist. Finally, culturally there are vastly different understandings of gender across countries and contexts. To insist on one - relatively recent white western - model as correct is deeply problematic.

Turning to process we need to ask ourselves what is going on that people seem to be so invested in these 'debates' at the moment, and that they are so prominent in mainstream and social media. I have three thoughts that I think are important to keep in mind, but would also refer readers to trans feminists like Julia Serano (2016), Juno Roche (2019), artist Travis Alabanza, and Ruth Pearce (2018) who write eloquently on these matters.

First, there is a long history of different groups of feminists being pitched against each other, often represented in the media as embroiled in a kind of 'cat fight'. The current pitching of trans feminists against 'gender critical feminists' is just the current version of this. In terms of who it serves, I guess it seems obvious to me who benefits from huge swathes of feminists focusing on this rather than on dismantling the patriarchy. It is worth recognising that most of the concern is around trans women and girls, and transfeminine people, not about trans men and boys, and transmasculine people. We need to reflect on the misogyny which has always policed those perceived as moving towards femininity far more than those moving towards masculinity, whatever their gender or sexual identities. 
Second, it serves existing systems and structures of power for people to blame more marginalised groups for their difficulties rather than questioning - or dismantling - those systems and structures. We see this in the blaming of immigrants for societal ills despite all evidence to the contrary; we see it in the demonising of individuals with mental health problems as dangerous to others when we know they are far more dangerous to themselves and their problems are likely far more systemic than they are individual; and we see it in the representing of trans people as violent predators or as endangering children through social contagion, precisely echoing the gay moral panic back in the 1980s.

Finally, I would return to my earlier point about sitting with our experience as victims and perpetrators, oppressed and oppressor. It is incredibly hard for those who have been fighting hard for people who've been oppressed and victimised for years to acknowledge that some of what they have done may have hurt or excluded others. Black feminists, trans feminists, lesbian feminists, working class feminists, and feminists in the global South, have all pointed out that the battles which seem highest priority for mainstream feminism have often been relatively unimportant - or even actively harmful - for them. The answer is not to defend against these criticisms, to position the critics as angry, difficult or crazy, or to deny them the status of womanhood entirely, the answer is - again - to learn to sit with the intense discomfort such conversations bring up, and to find ways to listen across difference.

\section{What for you is the relationship between gender, feminism and sexuality?}

Again to synopsise a lot of what is covered in Queer and Gender, for me gender and sexuality are interwoven within heteronormativity. We're culturally assumed to be either a man or a woman, and to be attracted to either men or women, and our identity is defined by this. In both cases, one side of the binary (men, straight people) is regarded as the norm and given high status and the other as less normal and given lower status (women, gay people). As previously mentioned, these binaries and hierarchies are also intrinsically linked to those around race, class, disability, age, location, mental health status, etc. The further binary of trans (changing from gender assigned at birth) and cis (remaining in gender assigned at birth), has also become interwoven with this, such that cis people are also seen as more normal and granted higher status than trans people.

Therefore, to my mind, all of these areas fall under the remit of feminism: gender and sexuality, but also race, class, disability, age, species... We simply can't fight gender oppression without also fighting homophobia, biphobia, and transphobia, being explicitly anti-capitalist and anti-racist, addressing climate change and its impact on the global South, engaging with body normativity and benefits, immigration and asylum, etc. As Flavia Dzodan (2011: n.p.) put it, 'my feminism will be intersectional or it will be bullshit'.

In Gender: $A$ graphic guide, you write about intersectional analysis and the importance of incorporating awareness of 'race, class, sexuality, disability, nationality, ethnicity, age, generation, geographical location, faith and more' (p. 5) into understanding how gender operates. How would you say intersectional analysis informs your work?

Deeply, and - of course - I am still learning. For me the people who I'm learning the most from at the moment are intersectional feminist thinkers and Buddhist teachers, and those who are weaving these ideas and practices together. Intersectional feminism makes more sense of my own lived experience - and that of the people I speak to - than the other ideas which I've engaged with over the years, and Buddhist teachings are a fruitful place to find practices which enable us to sit with the kinds of discomfort and distress that I've spoken about here. Together, for me, the work of people like bell hooks (1981), Audre Lorde (1984), Kai Cheng Thom (2019), Pema Chödrön (2000), Thich Nhat Hanh (1985), and Lama Rod Owens (Owens \& Syedullah, 2016) offer vital ways finding compassion for ourselves and others navigating these terrifying times, and forging new systems and structures for working together across our sharedness and difference.

In Gender: A graphic guide, there are several pages about non-binary experiences. What are your thoughts about the increasing number of people who are claiming this identity, as a non-binary person yourself?

It interests me that the numbers here vary radically depending on how you frame the question. It's similar to research around bisexuality. Studies which ask how many young people identify as something other than gay or straight come up with figures of between $1 \%$ and $10 \%$. Studies which ask how many young people experience attraction somewhere between 'exclusive heterosexuality' and 'exclusive homosexuality' come up with figures over $40 \%$. Similarly, with non-binary gender it seems that around $0.4-2 \%$ of people identify in this way given the opportunity. However, studies which ask the general population whether they experience themselves as to some extent 'the other gender, both genders, or neither gender' find that over a third experience themselves in such ways. When I ask people in workshops to list the stereotypes of being a 'real man' or a 'real woman', virtually nobody locates themselves on either list. Obviously even the framing of such questions assumes a Western binary understanding of gender which would not translate globally.

So clearly few people experience themselves on either side of a rigid, stereotypical gender binary, and many people would locate themselves somewhere on a spectrum given a choice. Also, as I mentioned before, many 
cultures worldwide, and across time, have had something other than a binary gender system and/or have understood masculinity and femininity in radically different ways to our current cultural understanding.

My thoughts are that identifying as non-binary potentially opens up the possibility for other people to be open about their experiences of gender diversity. The explosion terms for genders beyond man and women helps people to recognise that there are many different ways in which to identify, express and experience your gender, and hopefully find ways that are more comfortable and congruent for them, and communities of support around this. Of course, as with all things, identity labels have the potential to constrain options and close things down, just as they can expand possibilities and open things up. It's important to be cautious around new community norms about what a 'good' or 'proper' non-binary person would be like, any sense that people have to remain in fixed identity categories for a lifetime, and the tendency - as in any new group - for the most visible role models to end up being young, white, slim, non-disabled, wealthy, masculine-of-centre people.

\section{Your book Queer: A graphic history was a huge success. Did you expect it to become so popular?}

As I mentioned earlier, not at all. I am so glad now that I didn't pass up the opportunity! I think I owe Icon a lot of gratitude for asking me, and also for recognising what they had on their hands once we were writing the book. Initially it was planned to go straight into their 'introducing' series as a small book on queer theory alongside the ones on Marx, Freud and the like. However, they recognised the potential for much wider appeal - and how extraordinary Jules's illustrations were - and decided to go with a stand-alone book in a large glossy format initially instead. I'm sure that format and title are a big part of its popularity.

It's also very exciting that we've been able to follow up Queer with graphic guides on gender and sexuality, in order to delve much deeper into those topics. These subsequent books have also had the freedom to aim more explicitly at a general audience instead of staying too close to queer/gender/sexuality studies in an academic sense. Icon are hoping to publish books on many of the intersections we've talked about today from authors and illustrators with expertise in those areas, which will be incredibly helpful - I think - given how vital these areas are, how pivotal they have become, and how difficult people often find them emotionally.

We've also been able to gradually give our key characters working through the book more of their own character arcs and storylines, to bring the books somewhat close to a graphic novel despite being non-fiction. It's very fulfilling to keep playing with what is possible within this genre. Of course my dream - following Alison Bechdel would be one day to make the leap from graphic novel to musical!

\section{What are your plans for future work in the comics genre?}

I'm very keen to keep working with Kiera and Jules on graphic guides if at all possible. A couple of publications that I would like to write in the coming years are on love and on mental health. However I'm giving myself at least a year off right now to adjust to being self-employed and to deal with various big changes and traumas in my life in the past year which have certainly given me even more motivation to write about relationships and mental health!

I also produce occasional zines and workbooks alone, and with Justin and Alex, which incorporate my own illustrations. Given that most of my creating time goes to writing or speaking, it's good to keep my hand in with some drawing, and I'd like to give myself more time for that in the coming years.

Finally I'm also slowly working on my own series of comics - perhaps to work towards an eventual graphic memoir or self-help/memoir mash-up. The focus of these is the plurality of selfhood: a theme which fits well for me with queer and critical social psychology understandings, as well as many Buddhist and therapeutic approaches. There is a burgeoning movement of mental health activists reclaiming diagnoses of Dissociative Identity Disorder ${ }^{1}$ (previously Multiple Personality Disorder) and developing plural pride, at the same times as many trauma-informed therapies already conceptualise the self as plural and advocate for improving communication between - for example - inner child or inner critic states.

I've been personally working with plurality for some time now and have found it an immensely helpful way to make sense of my experience. I also feel it has some of the political potential I've spoken about to sit with - for example - both victim and perpetrator potentials in ourselves, and to allow that to inform our engagement with the wider world. Working - as I do now - as a writing mentor, these themes also come up a lot in the creative process as writers struggle with their inner critics, or find ways to return to earlier parts of themselves who are able to be freely imaginative, rather than caught up in the sense that they must be productive or create certain kinds of content or please certain imagined audiences. Plurality may also be helpful in enabling people - whether trans or cis - to communicate with past and present, and/or differently gendered, aspects of themselves.

I've used comics to time-travel through my life, and to support aspects of me that have become stuck by developing and bringing in other aspects who have the skills they need. I share the comics on my website as well as through free zines which take readers through the creative methods they might use to do the same kinds of work/play. Comics are definitely a big part of the future for me.

\footnotetext{
${ }^{1}$ DSM-5 300.14 (F44. 81); ICD-10-CM F44.81.
} 


\section{REFERENCES}

Barker, M. J. (2016). Queer: A graphic history. London: Icon Books.

Barker, M.-J. (2018). Rewriting the Rules: An anti self-help guide to love, sex and relationships. Second edition. London: Routledge.

Barker, M.-J. (2019). Good Practice Across the Counselling Professions 001: Gender, sexual, and relationship diversity (GSRD). BACP: Leicestershire.

Barker, M.-J. (2018). The Psychology of Sex. London: Routledge.

Barker, M. J. and Gabb, J. (2016). The Secrets of Enduring Love: How to make relationships last. London: Random House.

Barker, M.-J. and Hancock, J. (2017). Enjoy Sex (How, When and IF You Want to): A practical and inclusive guide. London: Icon Books.

Barker, M.-J. and Iantaffi, A. (2019). Life Isn't Binary: On being both, beyond, and in-between. London: Jessica Kingsley.

Barker, M., Richards, C., Jones, R., Bowes-Catton, H., Plowman, T., Yockney, J. and Morgan, M. (2012). The Bisexuality Report: Bisexual inclusion in LGBT equality and diversity.

Barker, M.-J. and Scheele, J. (2019). Gender: A graphic guide. London: Icon Books.

Chödrön, P. (2000). When Things Fall Apart: Heart advice for difficult times. Shambhala Publications.

Dzodan, F. (2011). My feminism will be intersectional or it will be bullshit. Tiger Beatdown, 10.

Gill, R. and Gill, R. M. (2007). Gender and the Media. Cambridge: Polity.

Hanh, T. N. (1985). A guide to walking meditation. Fellowship, 51(10-11), 23.

Harvey, L. and Gill, R. (2011). Spicing it up: Sexual entrepreneurs and the sex inspectors. In Gill, R. \& Scharff, C. (eds.) (2011) New Femininities and Sexual Citizenship (pp. 52-67). Basingstoke: Palgrave.

hooks, b. (1981). Black Women and Feminism. Boston: South End Press.

Iantaffi, A. and Bockting, W. O. (2011). Views from both sides of the bridge? Gender, sexual legitimacy and transgender people's experiences of relationships. Culture, Health \& Sexuality, 13(03), 355-370.

Iantaffi, A. and Barker, M.-J. (2017). How to Understand Your Gender: A practical guide for exploring who you are. London: Jessica Kingsley

Kinsey, A. C., Pomeroy, W. B. and Martin, C. E. (1948). Sexual Behavior in the Human Male. Philadelphia: Saunders.

Kinsey, A. C., Pomeroy, W. B., Martin, C. E. and Gebhard, P. H. (1953). Sexual Behavior in the Human Female. Philadelphia: Saunders.

Lorde, A. (1984). Sister Outsider: Essays and speeches. New York: The Crossing Press.

Owens, L. R. and Syedullah, J. (2016). Radical Dharma: Talking race, love, and liberation. Berkeley, CA: North Atlantic Books.

Pearce, R. (2018). Understanding Trans Health: Discourse, power and possibility. Bristol, UK: Policy Press.

Roche, J. (2019). Trans Power: Own your gender. London: Jessica Kingsley Publishers.

Serano, J. (2016). Whipping Girl: A transsexual woman on sexism and the scapegoating of femininity. Abingdon, UK: Hachette UK.

Thom, K. C. (2019). I Hope We Choose Love. Vancouver, Canada: Arsenal Pulp Press.

Websites:

http://www.biuk.org/

http:// criticalsexology.org.uk/

www.megjohnandjustin.com

www.rewriting-the-tules.com

https://senseaboutsex.wordpress.com/

http://travisalabanza.co.uk/

Citation: Ryan-Flood, R. (2020). Interview with MJ Barker. Feminist Encounters: A Journal of Critical Studies in Culture and Politics, 4(1), 02. https://doi.org/10.20897/femenc/7906

Copyright (C) 2020 by Author/s and Licensed by Lectito BV, Netherlands. This is an open access article distributed under the Creative Commons Attribution License which permits unrestricted use, distribution, and reproduction in any medium, provided the original work is properly cited. 